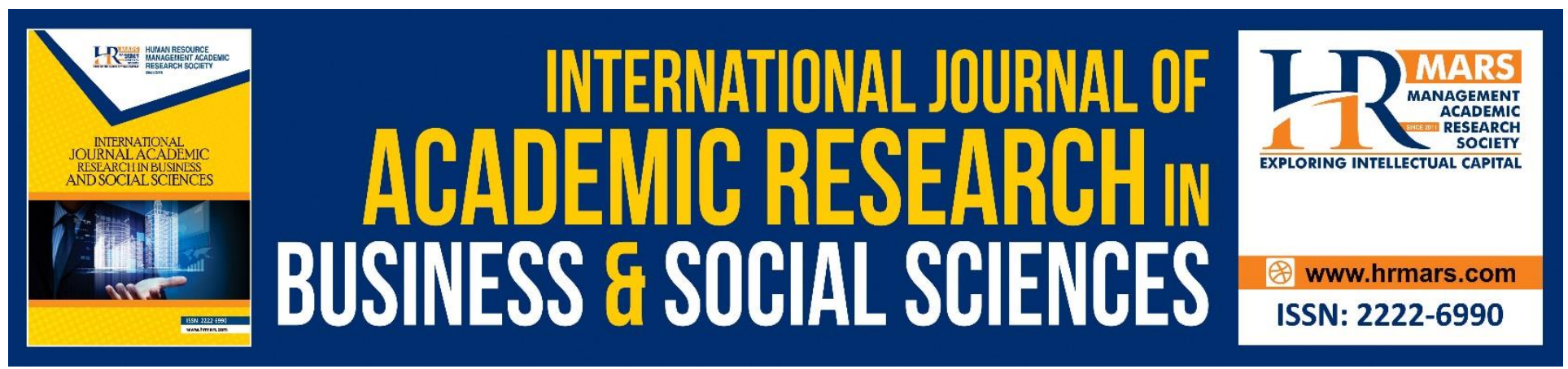

\title{
Black-Scholes Models with Inherited Time and Price Memory
}

\author{
Mahmoud Ali Jaradat
}

To Link this Article: http://dx.doi.org/10.6007/IJARBSS/v8-i12/5180

DOI: $10.6007 /$ IJARBSS/v8-i12/5180

Received: 02 Nov 2018, Revised: 19 Dec 2018, Accepted: 25 Dec 2018

Published Online: 30 Dec 2018

In-Text Citation: (Jaradat, 2018)

To Cite this Article: Jaradat, M. A. (2018). Black-Scholes Models with Inherited Time and Price Memory. International Journal of Academic Research in Business and Social Sciences, 8(12), 1153-1160.

Copyright: (C) 2018 The Author(s)

Published by Human Resource Management Academic Research Society (www.hrmars.com)

This article is published under the Creative Commons Attribution (CC BY 4.0) license. Anyone may reproduce, distribute, translate and create derivative works of this article (for both commercial and non-commercial purposes), subject to full attribution to the original publication and authors. The full terms of this license may be seen at: http://creativecommons.org/licences/by/4.0/legalcode

Vol. 8, No. 12, 2018, Pg. 1153 - 1160

http://hrmars.com/index.php/pages/detail/IJARBSS

JOURNAL HOMEPAGE

Full Terms \& Conditions of access and use can be found at http://hrmars.com/index.php/pages/detail/publication-ethics 


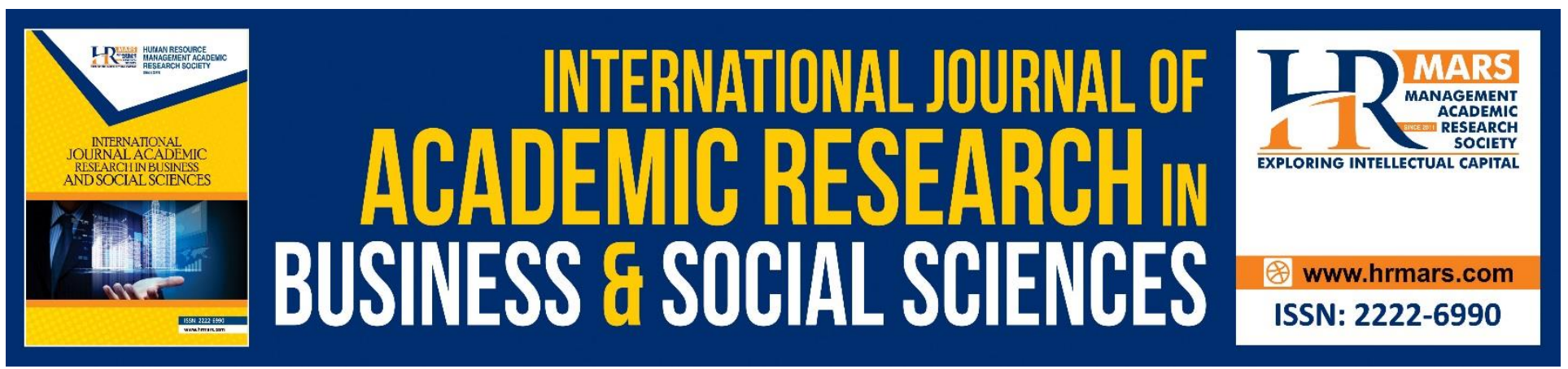

\title{
Black-Scholes Models with Inherited Time and Price Memory
}

\author{
Mahmoud Ali Jaradat \\ Department of Finance and Banking, Al al-Bayt University, P.O.BOX 130040, Mafraq 25113, Jordan. \\ Email: mahmoud.jaradat@ymail.com
}

\begin{abstract}
In this study, we examine three Black-Scholes option pricing models with inherited time and assess price memories. In other words, we take into consideration the reliance of these models on both the current state and the history of changes. A solution in the form of a bivariate time-price fractional power series is proposed for these models to study the shared influence of the memory index in both the time and price values. The findings of this study agree with the existing solutions in the literature for the classical option pricing integer-order cases. Therefore, the suggested scheme is strongly recommended to study further memory indexed financial models.
\end{abstract}

Keywords: Fractional Black-Scholes; Memory index; Fractional time-price power series solution.

\section{Introduction}

Option valuation plays a vital role on derivative markets and financial investment. Under certain hypotheses, Black and Scholes derived a theoretical valuation model for options that relies only on the price of the stock, time, and variables that are considered to be known scalars. Therefore, in option and stock ideal scenario, "it is possible to create a hedged position, consisting of a long position in the stock and a short position in the option, whose value will not depend on the price of the stock, but will depend only on time and the values of known constants" (Black\&Scholes, 1973). This model remains the hallmark of option trading and provides a mathematical validity to the activities of the European and American call or put options.

In fact, the Black-Scholes model is financial stochastic differential equations in nature. However, based on a combination of dynamic hedging technique, Ito calculus, and the no-arbitrage principle, it is demonstrated that these models can be transformed to linear evolutionary partial differential equations with variable coefficients (Gazizov\&lbragimov, 1998), somewhat similar to the well-known diffusion equation, of the form

$$
\frac{\partial W(x, t)}{\partial t}+\frac{\xi^{2}(x, t)}{2} x^{2} \frac{\partial^{2} W(x, t)}{\partial x^{2}}+r(t) x \frac{\partial W(x, t)}{\partial x}-r(t) W(x, t)=0
$$

where $W(x, t)$ the European call option price at asset price $x \in \mathbb{R}^{+}$and at time $t \in(0, T), T$ is the maturity, $r(t)$ is the risk free interest rate, and $\xi(x, t)$ is the volatility function of underlying asset. If $E$ represents 
the expiration price for the option, then the value of the European call option $W_{c}(x, t)=\max \{x-E, 0\}$ and the European put option $W_{p}(x, t)=\max \{E-x, 0\}$.

Recently, with the revolution of fractional calculus, it has been demonstrated that the noninteger order derivatives can reflect memory and heredity features ingrained in the processes (Du, Wang, \& Hu, 2013). Moreover, this memory phenomenon is not necessarily accompanied to the time variable, but also it could be accompanied by other variables (Pandey, Näsholm, \& Holm, 2016). Our motivation in this work is to look at the Black-Scholes model in a wider frame by replacing all the integer derivatives in equation (1.1) by non-integer ones. In other words, we aim to examine analytic solutions of the Black-Scholes model with inherited memory in both the time and price coordinates.

The rest of the paper is organized as follows: In Section 2, we propose a solution representation for Black-Scholes option pricing models with inherited time and assess price memories. In Section 3, we employ the corresponding power series method to extract closed-form solutions for three BlackScholes option pricing models. Finally, some concluding remarks are provided in Section 4.

\section{A solution representation of Black-Scholes models}

In this section, we provide a solution representation for Black-Scholes option pricing models with inherited time and assess price memories in terms of a bivariate fractional power series.

Definition 2.1. Let $n-1<\alpha<n \in \mathbb{N}$ and $W(x, t)$ be an appropriate time-price function. Then the time-fractional derivative, in Caputo sense, of order $\alpha>0$ is defined by

$$
\frac{\partial^{\alpha} W(x, t)}{\partial t^{\alpha}}=\frac{1}{\Gamma(n-\alpha)} \int_{0}^{t}(t-\tau)^{n-\alpha-1} \frac{\partial^{n} w(x, \tau)}{\partial \tau^{n}} d \tau .
$$

Similarly, we can price-fractional A direct consequence of with $n-1<\alpha<n$ yields

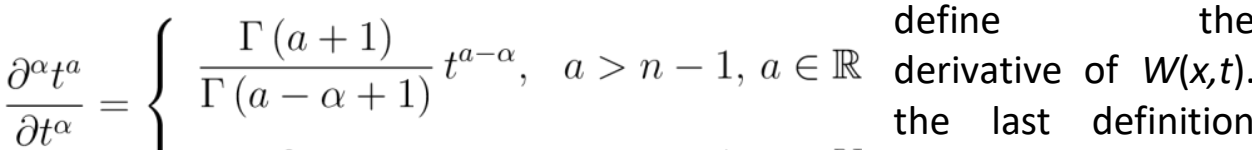

$$
\begin{aligned}
& 0 \quad, \quad a \leq n-1, a \in \mathbb{N} \text { that }
\end{aligned}
$$

Further, it enough to restrict our attention to the case where $\alpha \in(0,1)$ since

$$
\frac{\partial^{\alpha} W(x, t)}{\partial t^{\alpha}}=\frac{\partial^{\alpha-(n-1)} W^{(n-1)}(x, t)}{\partial t^{\alpha-(n-1)}}
$$

for an arbitrary fractional derivative order $n-1<\alpha<n$, where $\alpha-(n-1) \in(0,1)$.

Definition 2.2. A time-price fractional power series representation centered at origin is an infinite series of the form

$$
\sum_{i+k=0}^{\infty} \xi_{i k} t^{i \alpha} x^{k \gamma}=\underbrace{\xi_{00}}_{i+k=0}+\underbrace{\xi_{10} t^{\alpha}+\xi_{01} x^{\gamma}}_{i+k=1}+\underbrace{\xi_{20} t^{2 \alpha}+\xi_{11} t^{\alpha} x^{\gamma}+\xi_{02} x^{2 \gamma}}_{i+k=2}+\cdots,
$$

where $i, k \in \mathbb{N}^{*}, t, x \geq 0$ are variables, and $\xi_{i k} \in \mathbb{R}$ are coefficients of the series.

Theorem 2.3. (Jaradat, Alquran, \& Al-Khaled,2018) Suppose that the time-price function $W(x, t)$ can be written in the form (2.3) on $\Lambda=\left\{(t, x): 0 \leq t<R_{t}, 0 \leq x<R_{x}\right\}$. If $\frac{\partial^{n \alpha}}{\partial t^{n \alpha}} \frac{\partial^{m \gamma}}{\partial x^{m \gamma}}[W(x, t)] \in \mathcal{C}\left(\left(0, R_{t}\right) \times\left(0, R_{x}\right)\right)$ for $n, m \in \mathbb{N}$, then for all $(t, x) \in \Lambda, \alpha, \gamma \in(0,1)$, and $r, s \in$ Nwe have 
INTERNATIONAL JOURNAL OF ACADEMIC RESEARCH IN BUSINESS AND SOCIAL SCIENCES

Vol. 8, No. 12, Dec, 2018, E-ISSN: 2222-6990 @ 2018 HRMARS

$$
\begin{aligned}
\frac{\partial^{n \alpha}}{\partial t^{n \alpha}} \frac{\partial^{m \gamma}}{\partial x^{m \gamma}}[W(x, t)] & =\sum_{\substack{i+k=n+m \\
i \geq n, k \geq m}}^{\infty} \xi_{i k} \frac{\Gamma(i \alpha+1) \Gamma(k \gamma+1)}{\Gamma((i-n) \alpha+1) \Gamma((k-m) \gamma+1)} t^{(i-n) \alpha} x^{(k-m) \gamma} \\
& =\sum_{i+k=0}^{\infty} \xi_{i+n, k+m} \frac{\Gamma((i+n) \alpha+1) \Gamma((k+m) \gamma+1)}{\Gamma(i \alpha+1) \Gamma(k \gamma+1)} t^{i \alpha} x^{k \gamma} .
\end{aligned}
$$

Consequently, by substituting $x=0$ and $t=0$ into (2.4), we obtain the following form for the coefficients

$$
\xi_{i k}=\frac{\frac{\partial^{i \alpha}}{\partial t^{i \alpha}} \frac{\partial^{k \gamma}}{\partial x^{k \gamma}}[W(0,0)]}{\Gamma(i \alpha+1) \Gamma(k \gamma+1)}
$$

\section{An analytical solution of Black-Scholes models}

In this section, we examine three Black-Scholes option pricing models with inherited time and price memories and provide their solutions analytically in terms of a fractional power series representation that endowed with time and price fractional derivative orders. Ultimately, the solutions are given in closed-forms that agree with the existing solutions in the literature for the integer-order cases. In all our models, we assume that $t, x \geq 0$.

Model 1. Consider the Black-Scholes model with time and price memory indices $\alpha, \gamma \in(0,1)$ :

$$
\frac{\partial^{\alpha} W(x, t)}{\partial t^{\alpha}}+x^{2 \gamma} \frac{\partial^{2 \gamma} W(x, t)}{\partial x^{2 \gamma}}+0.5 x^{\gamma} \frac{\partial^{\gamma} W(x, t)}{\partial x^{\gamma}}-W(x, t)=0
$$

subject to the initial condition

$$
W(x, 0)=x^{3 \gamma}
$$

We seek a solution to (3.1) and (3.2) in the expansion form

$$
W(x, t)=\sum_{i+k=0}^{\infty} \xi_{i k} t^{i \alpha} x^{k \gamma}
$$

By implementing the initial condition into (3.3), we acquire the initial solution terms $\xi_{03}=1$ and $\xi_{0 k}=$ 0 for $k \in N^{0}-\{3\}$. Now, plugging all the related formulas (2.4) into (3.1) and balancing the analogous terms to get the following difference formulas for $\xi_{i k}$ :

$$
\begin{array}{cc}
\frac{\Gamma((i+1) \alpha+1)}{\Gamma(i \alpha+1)} \xi_{i+1, k}-\xi_{i k} & \\
\frac{\Gamma((i+1) \alpha+1)}{\Gamma(i \alpha+1)} \xi_{i+1, k}+(0.5 \Gamma(\gamma+1)-1) \xi_{i k} & k=0 \\
\frac{\Gamma((i+1) \alpha+1)}{\Gamma(i \alpha+1)} \xi_{i+1, k}+\left(\frac{\Gamma(k \gamma+1)}{\Gamma((k-2) \gamma+1)}+\frac{0.5 \Gamma(k \gamma+1)}{\Gamma((k-1) \gamma+1)}-1\right) \xi_{i k}=0 ; & k \geq 2
\end{array}
$$

Solving recursively equations (3.4) for the coefficients $\xi_{i k}$, we acquire

$$
\begin{aligned}
& \xi_{i 3}=\left(1-\frac{\Gamma(3 \gamma+1)}{\Gamma(\gamma+1)}-\frac{0.5 \Gamma(3 \gamma+1)}{\Gamma(2 \gamma+1)}\right)^{i} \frac{1}{\Gamma(i \alpha+1)} ; \quad i \geq 0 \\
& \xi_{i k}=0
\end{aligned}
$$

Thus, the time-price memory solution of Black-Scholes model (3.1) - (3.2) is given in a closed-form as 


$$
\begin{aligned}
W(x, t) & =\sum_{i=0}^{\infty} \xi_{i 3} t^{i \alpha} x^{3 \gamma} \\
& =x^{3 \gamma} \sum_{i=0}^{\infty}\left(1-\frac{\Gamma(3 \gamma+1)}{\Gamma(\gamma+1)}-\frac{0.5 \Gamma(3 \gamma+1)}{\Gamma(2 \gamma+1)}\right)^{i} \frac{t^{i \alpha}}{\Gamma(i \alpha+1)} \\
& =x^{3 \gamma} E_{\alpha}\left(\left(1-\frac{\Gamma(3 \gamma+1)}{\Gamma(\gamma+1)}-\frac{0.5 \Gamma(3 \gamma+1)}{\Gamma(2 \gamma+1)}\right) t^{\alpha}\right),
\end{aligned}
$$

where $E_{\alpha}(\cdot)$ is the well-known Mittag-Leffler function. We remark here as $\gamma \rightarrow 1$, we acquire the timefractional solution of (3.1)-(3.2)

$$
W(x, t)=x^{3} E_{\alpha}\left(-6.5 t^{\alpha}\right),
$$

which is in agreement with the solution provided in (Edeki, Ugbebor, \&Owoloko, 2017) using the projected differential transformation method. Moreover, as $\alpha, \gamma \rightarrow 1$, we acquire the solution for the Black-Scholes integer-order model of (3.1)-(3.2)

$$
\begin{aligned}
W(x, t) & =x^{3} \sum_{i=0}^{\infty} \frac{(-6.5 t)^{i}}{i !} \\
& =x^{3} e^{-6.5 t} .
\end{aligned}
$$

Model 2. Consider the Black-Scholes model with time and price memory indices $\alpha, \gamma \in(0,1)$ :

$$
\frac{\partial^{\alpha} W(x, t)}{\partial t^{\alpha}}=\frac{\partial^{2 \gamma} W(x, t)}{\partial x^{2 \gamma}}+(\lambda-1) \frac{\partial^{\gamma} W(x, t)}{\partial x^{\gamma}}-\lambda W(x, t)
$$

subject to the initial condition

$$
W(x, 0)=E_{\gamma}\left(x^{\nu}\right)-1 .
$$

Again, we assume the solution of (3.9) and (3.10) has the form

$$
W(x, t)=\sum_{i+k=0}^{\infty} \xi_{i k} t^{i \alpha} x^{k \gamma}
$$

By implementing the initial condition into (3.11), we acquire the initial solution terms $\xi_{00}=0$ and $\xi 0 k=\frac{1}{\Gamma(k \gamma+1)}$ for $k \geq 1$. Now, plugging all the related formulas (2.4) into (3.9) and balancing the analogous terms to get the following difference formula for the coefficients $\xi_{i k}$ : $\frac{\Gamma((i+1) \alpha+1)}{\Gamma(i \alpha+1)} \xi_{i+1, k}=\frac{\Gamma((k+2) \gamma+1)}{\Gamma(k \gamma+1)} \xi_{i, k+2}+(\lambda-1) \frac{\Gamma((k+1) \gamma+1)}{\Gamma(k \gamma+1)} \xi_{i, k+1}-\lambda \xi_{i k}$.

(3.12) Solving recursively equations (3.12) for the coefficients $\xi_{i k}$, we acquire

$$
\begin{array}{ll}
\xi_{i 0}=\frac{(-1)^{i+1} \lambda^{i}}{\Gamma(i \alpha+1)} ; \quad & i \geq 0 \\
\xi_{0 k}=\frac{1}{\Gamma(k \gamma+1)} ; \quad & k \geq 1 \\
\xi_{i k}=0 ; & \text { otherwise. }
\end{array}
$$

Thus, the time-price memory solution of Black-Scholes (3.9)-(3.10) is given in a closed-form as 
INTERNATIONAL JOURNAL OF ACADEMIC RESEARCH IN BUSINESS AND SOCIAL SCIENCES

Vol. 8, No. 12, Dec, 2018, E-ISSN: 2222-6990 @ 2018 HRMARS

$$
\begin{aligned}
W(x, t) & =\sum_{i=1}^{\infty} \frac{(-1)^{i+1} \lambda^{i}}{\Gamma(i \alpha+1)} t^{i \alpha}+\sum_{k=1}^{\infty} \frac{1}{\Gamma(k \gamma+1)} x^{k \gamma} \\
& =E_{\gamma}\left(x^{\gamma}\right)-E_{\alpha}\left(\lambda t^{\alpha}\right) .
\end{aligned}
$$

We remark here as $\gamma \rightarrow 1$, we acquire the time-fractional solution of (3.9)-(3.10)

$$
W(x, t)=e^{x}-E_{\alpha}\left(\lambda t^{\alpha}\right),
$$

which is in agreement with the solution provided in (Elbeleze, Kilicman, \&Taib, 2013) using a combination of the homotopy perturbation method, Sumudu transform, and He's polynomials. Moreover, as $\alpha, v \rightarrow 1$, we acquire the solution for the Black-Scholes integer-order model of (3.9)-(3.10)

$$
W(x, t)=e^{x}-e^{\lambda t}
$$

which is in agreement with the solution provided in (Edeki, Ugbebor, \&Owoloko, 2015) using the projected differential transformation method.

Model 3. Finally, we consider the following Black-Scholes model with time memory index $\alpha \in(0,1)$ :

$$
\frac{\partial^{\alpha} W(x, t)}{\partial t^{\alpha}}+0.08(2+\sin (x))^{2} x^{2} \frac{\partial^{2} W(x, t)}{\partial x^{2}}+0.06 x \frac{\partial W(x, t)}{\partial x}-0.06 W(x, t)=0
$$

subject to the initial condition

$$
W(x, 0)=\max \left\{x-25 e^{-0.06}, 0\right\} .
$$

Since the model endowed with only time memory index $\alpha$, we can assume that the solution to (3.17)-(3.18) has the form

$$
W(x, t)=\sum_{i=0}^{\infty} \xi_{i}(x) t^{i \alpha}
$$

Therefore,

$$
\frac{\partial^{n} W(x, t)}{\partial x^{n}}=\sum_{i=0}^{\infty} \xi_{i}^{(n)}(x) t^{i \alpha}
$$

and by using the fact (2.2), we have

$$
\frac{\partial^{\alpha} W(x, t)}{\partial t^{\alpha}}=\sum_{i=0}^{\infty} \xi_{i+1}(x) \frac{\Gamma((i+1) \alpha+1)}{\Gamma(i \alpha+1)} t^{i \alpha} .
$$

By implementing the initial condition into (3.19), we acquire the initial solution terms $\xi_{0}(x)=$ $\max \left\{x-25 e^{-0.06}, 0\right\}$. Now, plugging (3.19), (3.20), and (3.21) into (3.17) and balancing the analogous terms to get the following difference-differential equation for the coefficients $\xi_{i}(x)$ :

$$
\frac{\Gamma((i+1) \alpha+1)}{\Gamma(i \alpha+1)} \xi_{i+1}(x)+0.08(2+\sin (x))^{2} x^{2} \xi_{i}^{\prime \prime}(x)+0.06 x \xi_{i}^{\prime}(x)-0.06 \xi_{i}(x)=0
$$

In recursive manner, this consequently implies that for $i \geq 1$

$$
\xi_{i}(x)=\left(\max \left\{x-25 e^{-0.06}, 0\right\}-x\right) \frac{(0.06)^{i}}{\Gamma(i \alpha+1)} .
$$

Thus, the time memory solution of the Black-Scholes (3.17)-(3.18) is given in a closed-form as 


$$
\begin{aligned}
W(x, t) & =\max \left\{x-25 e^{-0.06}, 0\right\}+\left(\max \left\{x-25 e^{-0.06}, 0\right\}-x\right) \sum_{i=1}^{\infty} \frac{(0.06)^{i}}{\Gamma(i \alpha+1)} t^{i \alpha} \\
& =x+\left(\max \left\{x-25 e^{-0.06}, 0\right\}-x\right) E_{\alpha}\left(0.06 t^{\alpha}\right)
\end{aligned}
$$

which is in agreement with the solution provided in (Elbeleze, Kilicman, \&Taib, 2013). In particular, if $\alpha \rightarrow 1$, we have the exact solution

$$
W(x, t)=x+\left(\max \left\{x-25 e^{-0.06}, 0\right\}-x\right) e^{0.06 t}
$$

to the classical Black-Scholes of (3.17)-(3.18) (Edeki, Ugbebor, \&Owoloko, 2015).

\section{Concluding remarks}

In this study, we have provided analytical solutions for three Black-Scholes option pricing models endowed with memory index on time and price simultaneously. To the author's knowledge, this is the first attempt to examine the mutual impact of the time and price fractional derivatives of Black Scholes models. The solutions are given in the form of convergent fractional power series with easily accessible coefficients and without any restrictive presumptions. Moreover, these solutions generalized all the existing results regarding the integer and time-fractional versions of Black-Scholes models. This gives the opportunity to predict the European call option price from the time and assess price changes in the past.

\section{Contribution}

The outcomes of this research submit various contributions. For the theoretical side, the analytical scheme conducted in this study has shown the generality and independence of the Black-Scholes option pricing models with multi-memory indices. To the best knowledge of the author, this is the first attempt to consider Black-Scholes models in the proposed format where the time and the price endowed with fractional parameters. Further, analytical solutions have successfully obtained in terms of convergence power series in a fractional sense. From the side of practitioners, the obtained solutions of these models would contribute to utilizing the history of the European call option price to predict the present valuation for options.

\section{References}

Black, F., \& Scholes, M. (1973). The pricing of options and corporate liabilities. Journal of Political Economics, 81(3), 637-654.

Du, M., Wang, Z., \& Hu, H. (2013). Measuring memory with the order of fractional derivative. Scientific Reports, 3, 3431.

Edeki, S. O., Ugbebor, O. O., \&Owoloko, E. A. (2017). Analytical solution of the time-fractional order Black-Scholes model for stock option valuation on no dividend yield basis. IAENG International Journal of Applied Mathematics, 47(4), 407-416.

Edeki, S. O., Ugbebor, O. O., \&Owoloko, E. A. (2015). Analytical solutions of the Black-Scholes pricing model for European option valuation via a projected differential transformation method. Entropy, 17(11), 7510-7521. 
INTERNATIONAL JOURNAL OF ACADEMIC RESEARCH IN BUSINESS AND SOCIAL SCIENCES

Vol. 8, No. 12, Dec, 2018, E-ISSN: 2222-6990 C 2018 HRMARS

Elbeleze, A. A., Kili,cman, A., \&Taib, B. M. (2013). Homotopy Perturbation Method for Fractional Black-Scholes European Option Pricing Equations Using Sumudu Transform. Mathematical Problems in Engineering, 2013, 524852.

Gazizov, R. K., \&lbragimov, N. H. (1998). Lie symmetry analysis of differential equations in finance. Nonlinear Dynamics, 17(4), 387-407.

Jaradat, I., Alquran, M., \& Al-Khaled, K. (2018). An analytical study of physical models with inherited temporal and spatial memory. The European Physical Journal Plus, 133, 162.

Pandey, V., Näsholm, S. P., \& Holm, S. (2016). Spatial dispersion of elastic waves in a bar characterized by tempered nonlocal elasticity. Fractional Calculus and Applied Analysis, 19(2), 498-515. 